\title{
RECUSA DE INTERAÇÃO E ATOS DE AMEAÇA À FACE: PRESIDENTE JAIR BOLSONARO VERSUS JORNALISTAS
}

Danielle Zuma Capellani *

RESUMO: Neste artigo científico, observamos as estratégias discursivas nos turnos de fala institucional nas entrevistas televisivas do Presidente Jair Bolsonaro com jornalistas em duas situações comunicativas, no início da pandemia por COVID-19 no Brasil. Descrevemos como os jornalistas insistem, nos turnos de pergunta, por respostas efetivas do Presidente sobre o controle da pandemia no país, mas este, nos turnos de resposta, ameaça a face positiva dos jornalistas e negocia identidades situadas por meio de negação, de quem não é, eximindo-se da responsabilidade de gerir a crise sanitária. Utilizamos os pressupostos teóricos e metodológicos da Análise da Conversa para transcrever os dados e analisar a troca de turnos e a visão da Linguística Interacional para entender a interferência do mandato institucional e do cenário nas ações de negociação de identidades, turno a turno.

PALAVRAS-CHAVE: Análise da conversa; COVID-19; entrevista jornalística; identidades situadas; Linguística interacional.

\section{Introdução}

Neste artigo debatemos sobre as estratégias discursivas evidenciadas nos turnos de fala institucional do Presidente da República Jair Messias Bolsonaro em entrevista televisiva com jornalistas, ocasiões em que há recusa de interação e atos de ameaça à face dos profissionais da imprensa, perante seus apoiadores e militantes.

Desde a campanha eleitoral de 2018, o então candidato utilizava as redes sociais digitais como estratégia discursiva para se comunicar com os eleitores e não fazer pronunciamentos aos veículos de mídia tradicional, tendo inclusive se recusado a participar dos debates políticos, principalmente depois da ocasião da facada no abdômen em comício na cidade de Juiz de Fora (MG), em 06/09/2018, muitas vezes utilizada como justificativa para o não

\footnotetext{
* Doutora em Estudos da Linguagem pela Pontifícia Universidade Católica do Rio de Janeiro (PUC-Rio). Professora do Centro Universitário Ruy Barbosa (UniRuy).
} 
comparecimento às entrevistas e debates, mesmo que tenha concedido entrevista no leito do hospital, recuperando-se de uma cirurgia no intestino em função da facada, à Rede Record de Televisão, em 04/10/2018, mesmo dia do debate presidencial na Rede Globo de Televisão.

Como Presidente eleito, durante o ano de 2019, manteve a crítica constante à mídia tradicional e aos jornalistas, que, tratados de modo desrespeitoso em entrevistas coletivas, por vezes eram silenciados por representarem algum veículo específico, apontado como manipulador de informação ou instrumento de perseguição ao Presidente e à sua Administração como um todo. Em 16/01/2020, a Federação Nacional dos Jornalistas (FENAJ) divulgou o Relatório da Violência contra Jornalistas e Liberdade de Imprensa no Brasil - ano 2019, em que o Presidente Bolsonaro foi responsável direto por 121 casos (mais da metade do total) de ataques a veículos de comunicação e a jornalistas, sendo 114 ofensivas genéricas e generalizadas, além de 7 casos de agressões diretas a jornalistas.

Segundo a Presidenta da FENAJ, há ameaça à liberdade de imprensa e à integridade moral e física dos jornalistas no Brasil. Em 2019, no primeiro ano de governo, houve cinco casos de agressões em entrevistas/conversas com jornalistas. (https://fenaj.org.br/ataquesa-imprensa-explodem-com-bolsonaro/. Acesso 11 mar. 2021). Os casos aumentaram em 2020, quando, em função do aumento da pressão sofrida pelo Presidente durante a pandemia pelo COVID-19, suas reações se tornaram mais agressivas contra os jornalistas (ainda que não haja dados divulgados).

Este artigo científico é mais uma possibilidade de ratificar a importância das Ciências Humanas e da Linguagem para compreender os fenômenos que se processam na atualidade, nas relações entre governantes e a mídia, como um recurso para divulgar ações da Administração Pública aos cidadãos durante crises. Entender a relação com os profissionais de imprensa esclarece como os jornalistas têm ou não o respeito profissional assegurado.

\section{Dados}

Ao transcrever duas interações de dados de fala-em-interação institucional do Presidente Bolsonaro no ano de 2020, durante a pandemia do coronavírus em nosso país, percebemos que o Presidente se exalta, evita a interação com jornalistas, fazendo sobreposições às falas e desmerecendo as perguntas ao ser questionado sobre as ações do Governo Federal e do Ministério da Saúde no combate à Covid-19, ameaçando a face dos repórteres diante dos seus apoiadores. 
Foram transcritas, conforme as convenções da Análise da Conversa, de Gail Jefferson (SACKS, SCHEGLOFF, JEFFERSON, 1974), as interações institucionais ocorridas no "cercado" destinado aos jornalistas e apoiadores no Palácio da Alvorada, nos dias 20/04/2020 (“Eu não sou coveiro”) e 28/04/2020 (“E daí?”), coletadas por meio de vídeos postados no YouTube. Incluímos também em nossa análise a carta das Organizações Globo ao Gabinete de Segurança Institucional (GSI) sobre a decisão de os jornalistas não ficarem mais no referido local de entrada e saída do Presidente, no Palácio da Alvorada, em função da insegurança para os profissionais de imprensa, enviada no dia 25/05/2020 (https://oglobo.globo.com/brasil/falta-de-seguranca-faz-jornalistas-do-grupo-globo-deixar-plantao-no-alvorada-1-24445585 Acesso em 20 jun. 2020).

Desde a campanha eleitoral de 2018, Bolsonaro opta por não falar com a mídia tradicional, preferindo fazer pronunciamentos no YouTube ou mesmo divulgar ações de governo, incluindo demissão e admissão de cargos na Administração Pública, por Twitter. Nos dois primeiros anos de governo, houve ampliação do uso das redes sociais digitais pessoais do Presidente, sendo utilizadas por ele e seus filhos, sendo Carlos Bolsonaro um dos mentores do pai no uso das mídias sociais para fins políticos durante a governança.

Foram adotados conceitos da Linguística Interacional para observação dos dados, visando à análise da estrutura de participação e à observação das estratégias de ameaça à face dos jornalistas, nos turnos de suposta resposta do Presidente Bolsonaro. Os conflitos nas entrevistas evidenciam a perspectiva antidemocrática do atual governo, moralista nos costumes e socialmente intolerante, incapaz de lidar com situações de conflito e perguntas consideradas espinhosas, feitas por jornalistas de veículos de comunicação, mesmo que se saiba que cabe ao jornalista perguntar e ao entrevistado, responder. Além de compor o mandato institucional (MAYNARD, 1984) destes profissionais, como um de seus deveres, questionar o entrevistado sobre o que a opinião pública quer ou precisa saber, considerando, inclusive, que o entrevistado é o Presidente da República e estamos (ainda em 2021) vivendo uma pandemia, em que as demandas por esclarecimentos aumentam exponencialmente, assim como o número de mortes.

\section{Fala-em-interação institucional}

A análise sistemática da fala produzida em situações diárias de interação humana, i.e., é o estudo da fala-em-interação, em situações concretas de uso em ambiente natural de ocorrência da linguagem, a partir da transcrição de fragmentos de dados espontâneos, é o objeto de estudo da Análise da Conversa, assim como as falas institucionais, como verificado em 
nossos dados, em que os participantes estão orientados para suas identidades profissionais de Presidente da República e jornalista.

Apesar de originar-se na Sociologia praticada na década de 60 do século XX, distingue-se fortemente desta no que diz respeito aos objetos de estudo. Enquanto a Sociologia de Émile Durkheim ocupa-se com fenômenos de ordem macrossocial e com informações que podem ser tratadas estatisticamente, a Análise da Conversa observa fenômenos de ordem microssocial, que, transcritos, revelam a interação por meio da materialidade da língua e da organização dos turnos de fala. Em 1964, quando Harvey Sacks começou suas pesquisas pioneiras sobre a organização estrutural da linguagem no uso cotidiano, observou os níveis da ordem social que poderiam ser revelados na conversa cotidiana, cenário básico do uso da linguagem e universal às sociedades humanas. $\mathrm{O}$ autor aponta que a fala-em-interação é um fenômeno sistematicamente organizado e profundamente ordenado e que as interações ocorrem visando concordância e continuidade (SACKS, 1973), exatamente o contrário do observado nos nossos dados. A Análise da Conversa, portanto, ocupa-se do estudo das formas com que os enunciados realizam determinadas ações, em virtude de sua localização e de sua participação em sequências de ações.

Os falantes orientam-se pelo que foi dito imediatamente antes de suas falas. Nesse sentido, os interlocutores projetam uma próxima ação relevante que pode ser compreendida por um par de ações reconhecido convencionalmente, como pares adjacentes, como nos nossos dados, pergunta e resposta, por exemplo. Algumas características dos pares adjacentes são as seguintes: uma sequência de dois enunciados, que são adjacentes, produzidos por falantes diferentes, ordenados como uma primeira parte e uma segunda parte, de forma que a primeira parte de pergunta requer uma segunda parte específica de resposta, mesmo que, nos dados, os turnos do Presidente nem sempre têm o conteúdo esperado como resposta à pergunta feita, usando a mídia tradicional para confirmar seu comportamento de quem é agente de sua própria fala, em busca de uma autenticidade irresponsável, que, por muitas vezes, desrespeita o interlocutor.

A estrutura de participação da interação auxilia a percepção dos padrões interacionais expressos neste contexto (MOITA LOPES, 2001, 2002), nos nossos dados caracteriza-se pelos falantes (ora Presidente, ora jornalistas), pelos ouvintes ratificados (ora Presidente, ora jornalistas, alternando papéis), pelos ouvintes circunstanciais (militantes/apoiadores do Presidente que ficam mais próximos do mesmo no "cercado" e interferem na entrevista aplaudindo o Presidente ou rindo de suas respostas) e os expectadores das entrevistas (todos/todas nós em casa assistindo à TV ou acessando a Internet). 
Nas entrevistas jornalísticas realizadas no "cercado" do Palácio da Alvorada, como gênero de fala institucional, destacam-se as regras do sistema de tomada de turno 8, 9, 11, 12 e 14, modificadas da conversa cotidiana (SACKS; SCHEGLOFF; JEFFERSON, 1974, p. 730).

Regra 8: O que cada falante dirá não é fixo nem previamente especificado. Isto se dá porque não há agenda tópica, inclusive porque, ao questionar o Presidente estando no "cercado" do Palácio da Alvorada, a imprensa tenta sem sucesso pautar as entrevistas com questões relevantes no momento da pandemia. Além disso, há outras especificações, pois os primeiros turnos geralmente são perguntas (ou associações de declaração com pergunta) e os turnos seguintes são restringidos pelos primeiros de modo a serem pares adjacentes destes, isto é, respostas. Nos dados, observamos que o Presidente não responde às perguntas objetivamente, mas com expressões de desprezo à pergunta ou ao jornalista, como se estivesse interagindo com a claque de apoiadores, que o ovacionam (linhas 28-30).

Quadro 1 - Segmento [JB01: 23-301] exemplo da regra 8 do sistema de tomada de turno

\begin{tabular}{|l|l|l|}
\hline 23 & JB: & va-vamos o primeiro passo é esse. porque os pais ainda tão \\
\hline 24 & & com medo ainda. os pais tão com medo então é natural \\
\hline 25 & JOR 1: & é gradual= \\
\hline 26 & JB: & \multicolumn{1}{c|}{$=$ é gradual e tem que voltar à normalidade $=$} \\
\hline 27 & JOR 1: & \multicolumn{1}{|c|}{} \\
\hline 28 & & tivemos mais de 300 mortes. quantas mortes o senhor acha \\
\hline 29 & & que- \\
\hline 30 & JB: & ah ô cara quem fala de- eu não sou coveiro tá certo \\
\hline
\end{tabular}

Fonte: Dados transcritos a partir das interações obtidas no YouTube ${ }^{2}$

Regra 9: A distribuição dos turnos é fixa. Há três formas desta regra operar: a) o falante corrente pode selecionar o próximo falante, sendo o jornalista fazendo pergunta ao Presidente e o Presidente, por sua vez, selecionando o jornalista que "pode" perguntar, por representar um veículo que julga confiável (desde que a pergunta não seja espinhosa, segundo seus critérios); b) o próximo falante pode se autosselecionar, com o Presidente decidindo

\footnotetext{
1 A notação utilizada para indicar os trechos de discurso selecionados como exemplos foi criada para a localização deste trecho nas páginas de transcrição das entrevistas. A notação foi utilizada da seguinte forma: [JB01:01-07], em que as primeiras letras (JB) indicam as iniciais do nome do entrevistado Jair Bolsonaro e o número que segue esta letra indica a entrevista, sendo 01 para "Eu não sou coveiro" e 02 para "E dấ". Após os dois pontos indica-se a sequência de linhas em que o trecho do discurso ou segmento em análise está localizado. Neste caso, o intervalo da linha número 1 à linha número 7.

${ }^{2}$ A fonte de todos os quadros neste artigo científico são transcrições feitas por nós das entrevistas jornalísticas, conforme convenções da Análise da Conversa (SACKS; SCHEGLOFF; JEFEERSON, 1974) e disponíveis nos Anexos deste artigo científico, a partir de dados obtidos de publicações no YouTube, disponíveis em: https://youtu.be/aIpUbYjjdn0. Acesso em 20 jun. 2020 para "Eu não sou coveiro" e em: https://youtu.be/KGACSgIToUk. Acesso em 20 jun. 2020 para "E daí".
} 
que é momento de ele tomar o turno, seja diante dos apoiadores ou de jornalistas (exemplo do segmento abaixo, em que o Presidente interrompe o jornalista); c) o falante corrente pode estender seu próprio turno através de incrementos, o que acontece em muitas vezes em que o Presidente toma o turno e, quando julga conveniente, encerra a interação ou tentativa da mesma, em fala e/ou gesto (linhas 28-30).

Quadro 2 - Segmento [JB01: 27-30] exemplo da regra 9 do sistema de tomada de turno

\begin{tabular}{|l|l|l|}
\hline 27 & JOR 1: & \multicolumn{1}{c|}{$=$ hoje } \\
\hline 28 & & tivemos mais de 300 mortes. quantas mortes o senhor acha \\
\hline 29 & & que- \\
\hline 30 & JB: & ah ô cara quem fala de- eu não sou coveiro tá certo \\
\hline
\end{tabular}

Regra 11: Os exemplos de fala-em-interação que analisamos são contínuos, pois se desenvolvem pelo mesmo falante ou por outro, por uma sequência de lugares relevantes para transição ${ }^{3}$, com o mínimo de intervalo (gap), entretanto verificamos que há algumas sobreposições (linhas 14-15, sendo a sobreposição das linhas 6-7 com as palmas dos apoiadores) e encadeamentos na fala (linhas 9-10;12-13), em que o Presidente responde prontamente as perguntas feitas pelos jornalistas, desvalorizando-as ou sobrepondo a fala dos jornalistas para interrompê-los.

Quadro 3 - Segmento [JB01: 06-16] exemplo da regra 11 do sistema de tomada de turno

\begin{tabular}{|l|l|l|}
\hline 06 & APO: & =ehh [palmas] \\
\hline 07 & JB: & [okey ]? então essa \\
\hline 08 & & talvez seja o primeiro gesto é:: pra nós aqui voltarmos à \\
\hline 09 & & normalidade no tocante ao estudo aqui no Brasil= \\
\hline 10 & JOR 1: & $=$ a partir de \\
\hline 11 & & quando \\
\hline 12 & JB: & a partir de segunda-feira. não tá não tá batido o martelo ainda= \\
\hline 13 & JOR 1: & é \\
\hline 14 & & uma possibilida [de \\
\hline 15 & JB: & [(também) já conversei com o joão fernando \\
\hline 16 & & ele: acha que a ideia é boa vai conversar com o chefe de gp \\
\hline
\end{tabular}

Regra 12: Nas conversas analisadas são usadas técnicas de alocação (distribuição) de turno, como a regra dos pares adjacentes, em que uma primeira parte seleciona um próximo falante para uma determinada segunda parte do par, tornando-a relevante, como no par pergunta (linha 10) e resposta (linha 11), por exemplo.

\footnotetext{
${ }^{3}$ O lugar relevante para transição é basicamente o ponto no enunciado de um falante em que o outro pode tomar o turno por entender que este chegou ao fim, por ter concluído o conteúdo, por marcas prosódicas ou sintáticas que indicam finalização aparente.
} 
Quadro 4 - Segmento [JB02: 10-11] exemplo da regra 12 do sistema de tomada de turno

\begin{tabular}{|l|l|l|}
\hline 10 & JOR 3: & um plano pro ministro o ministro não vai apresentar um plano? \\
\hline 11 & JB: & o ministro que apresenta. \\
\hline
\end{tabular}

Regra 14: Certos mecanismos de reparo resolvem falhas ou violações nas tomadas de turno, assim como problemas gerados por fala simultânea e erros intraturno. Nos dados, há uma situação de reparo do jornalista (linha 35), porque o Presidente parece não saber de que ministro trata ao falar da saúde (linha 34).

Quadro 5 - Segmento [JB01: 31-35] exemplo da regra 14 do sistema de tomada de turno

\begin{tabular}{|l|l|l|}
\hline 31 & JOR 1: & Presidente, mais uma coisa \\
\hline 32 & JB: & não sou coveiro \\
\hline 33 & JOR 2: & como foi a reunião com o ministro teich? \\
\hline 34 & JB: & ministro ministro? \\
\hline 35 & JOR 2: & da saúde, ministro da saúde. \\
\hline
\end{tabular}

Além do sistema de tomada de turno, nas falas institucionais há algumas características objetivas e conceituais de mandato institucional, cenário (setting) e identidade institucional ou profissional. A noção de fala é considerada institucional porque nela pelo menos um dos participantes está orientado para objetivos específicos, relacionados às suas identidades institucionais e profissionais referentes à instituição em questão (cf. DREW \& HERITAGE, 1992), então temos tanto o Presidente quanto os jornalistas orientados para as suas tarefas, sendo o primeiro orientado para o ponto mais radical e de hierarquia rígida, militarista, que responde quando julga conveniente ou ameaça a face do outro (situação mais comum em nossos dados). Aos jornalistas cabe fazer perguntas que sejam de interesse público, por isso muitas vezes estas são interpretadas como espinhosas, assim como observado em entrevistas com candidatos à Presidência.

A fala institucional é associada também a um arquivo de possibilidades inferenciais e interpretativas particulares aos contextos institucionais, como o entrevistado responder as perguntas feitas, mas não inferimos que este entrevistado seja desrespeitoso com os entrevistadores, dando respostas rudes, o que de fato ocorre. Em contextos institucionais específicos, existe uma gama de possibilidades de interpretação das ações relativas a esse contexto. Como, por exemplo, no contexto de entrevista existe uma orientação para que o profissional evite expressões de concordância ou discordância com as respostas nos turnos dos entrevistados, assim como entre jornalistas e veículos de comunicação, na sociedade democrática, não há previsão de que estes se calem ou parem de perguntar a um entrevistado, seja quem for, mesmo em casos de desrespeito e autoritarismo. 
Os participantes, portanto, estão orientados para tarefas, restrições de conduta e procedimentos inferenciais relevantes para interagirem adequadamente uns com os outros, conforme seu mandato institucional, que envolve as tarefas e as metas-fim que os entrevistadores precisam alcançar por meio de sua interação com os entrevistados e que devem estar asseguradas antes do encerramento desta (MAYNARD, 1984; GARCEZ, 1996, 2002), garantidas por deferência e por cada um saber seu papel interacional e institucional no evento comunicativo.

\section{Cenário (setting)}

O segundo conceito envolvido nessa abordagem sobre fala institucional é o de cenário (setting). Mesmo sabendo que não é este que define a fala como institucional, já que a fala em questão será desse modo considerada se os participantes estiverem orientados para algum objetivo, ainda assim, o cenário onde se processa a interação, aliado à identidade dos participantes, indica a institucionalidade. Nos nossos dados, o "cercado" é o cenário que resta aos jornalistas para tentar entrevistar o Presidente. Por esta razão, também orienta a tarefa e a identidade discursiva do entrevistado Presidente da República e dos entrevistadores, uma vez que há os ouvintes circunstanciais apoiadores do Presidente, que são contrários à imprensa e se manifestam durante as entrevistas, atuando também como interlocutores na interação.

Causa interesse refletir se não seriam, em algumas ocasiões, os jornalistas ouvintes circunstanciais das conversas do Presidente com os militantes apoiadores e, por terem aguçado senso de oportunidade, aproveitam para realizar entrevistas, já que a entrada/saída do Palácio da Alvorada é uma área de circulação. Pode-se levantar essa hipótese, principalmente em função do desrespeito e inequívoca perturbação do Presidente ao se sentir obrigado a responder as perguntas.

Nesse aspecto, merece destaque o que resta a estes profissionais jornalistas como direitos e o que os limita, tendo que entrevistar o Presidente em um "cercado", em que estão envolvidos apoiadores, muitas vezes colocados a frente e contra a imprensa, já que ficam mais próximos do Presidente a ser entrevistado, e calam a voz da imprensa e a desvalorizam, como se replicassem a ação de seu líder.

Os jornalistas são constrangidos e sofrem ameaças verbais frequentes, em alguns casos houve risco à integridade física dos profissionais, o que provocou a decisão do Grupo Globo e da Folha de São Paulo de retirar seus jornalistas do "cercado", área para fazer cobertura no Palácio da Alvorada. O Grupo Globo informou a decisão em carta ao Gabinete de Segurança Institucional (GSI), em 25/05/2020, assinada por Paulo Tonet Camargo, Vice-Presidente de 
Relações Institucionais do Grupo Globo (Disponível em: https://oglobo.globo.com/brasil/falta-de-seguranca-faz-jornalistas-do-grupo-globo-deixar-plantao-no-alvorada-1-244455 85. Acesso em 20 jun. 2020)

No primeiro parágrafo da carta é explicitada a justificativa para a retirada dos jornalistas do cenário em questão: "são muitos os insultos e os apupos que os nossos profissionais vêm sofrendo dia a dia por parte dos militantes que ali se encontram, sem qualquer segurança para o trabalho jornalístico". E, como as agressões eram crescentes, a partir daquela data ficou decidido que os repórteres das Organizações Globo, "que têm como incumbência cobrir o Palácio da Alvorada, não mais comparecerão àquele local na parte externa destinada à imprensa".

A carta se encerra com a reiteração sobre a falta de segurança para os profissionais da imprensa: "Com a responsabilidade que temos com nossos colaboradores, e não havendo segurança para o trabalho, tivemos que tomar essa decisão”. Em nenhum dos cinco parágrafos da carta foram mencionados insultos dos "simpatizantes" ou "militantes" (termos da carta) que tenham sido estimulados pelo Presidente da República, o que é possível considerar sabendo de seu desinteresse em responder, do desrespeito com os jornalistas, do conteúdo das respostas e da frequente ovação dos participantes da claque ao adotar esta identidade e projetar para os jornalistas a identidade de inconvenientes.

\section{Negociação de identidades situadas e atos de ameaça à face}

$\mathrm{Na}$ Análise da Conversa, para que a identidade seja considerada relevante na análise, checamos o trabalho interacional em andamento no encontro e se os participantes estão orientados para ela.

A identidade discursiva refere-se ao papel interacional, como quem pergunta (o jornalista entrevistador) e quem responde (o Presidente entrevistado). Entretanto, é o aspecto situacional, conforme visão socioconstrucionista (MOITA LOPES, 2001, 2002), que se mostra mais relevante, sob dois aspectos: na situação comunicativa onde se processa a interação e na troca de turnos, pois assim verificamos as identidades contextuais (ZIMMERMAN, 1998), visíveis pelos participantes na exploração das estruturas da conversa as quais devem apresentar consequências para o rumo da interação, utilizando marcas verbais, paralinguísticas (como entonação, ênfase, fala interrompida) ou não-verbais (como o dedo em riste ou a mão em sinal de parar). Estas formas autoritárias, utilizadas com frequência em entrevistas, são recursos de o Presidente tentar controlar a interação, por vezes sendo perguntado e não se comportando como entrevistado, porque se exime de responder e/ou encerra o encontro, 
uma vez que parece acreditar que interacionalmente há mais assimetria de poder entre entrevistar e ser entrevistado do que de fato se verifica nas interações de entrevista televisiva nos veículos de comunicação tradicionais no Brasil.

Esta pretensa relação de poder provoca conflitos nas entrevistas, em que o presidente performa atos de ameaça à face positiva dos jornalistas, entendendo como face o conceito introduzido por Goffman (1967), como a imagem pública, negociada pelo falante nas interações para que seja socialmente aprovada, segundo as normas e valores estabelecidos pelos membros de uma comunidade. O conceito tem caráter intersubjetivo e social, porque se refere à autoapresentação e também ao prestígio e à reputação que são confirmados ou refutados na interação, com desejo de ser aceito (face positiva), bem como à manutenção da liberdade de ação e domínio do próprio território (face negativa).

As estratégias de polidez, por sua vez, visam reparar ou corrigir os atos de ameaça à face (BROWN; LEVINSON, 1978), que são atos intencionais e situados visando sobrepor o poder de um falante sobre o outro, em situação de conflito, expressos linguisticamente ou por inferências. Nos nossos dados, é o Presidente Jair Bolsonaro que ameaça a face positiva dos jornalistas e, em nenhum momento no curso da interação e nem posteriormente, usa qualquer estratégia de polidez para minimizar os danos potenciais à autoestima dos jornalistas. Não reconhece o desejo do jornalista ter sua imagem prestigiada (polidez positiva para reparar dano à face positiva) nem reconhece que o ouvinte quer sua intimidade preservada (polidez negativa, relacionada à face negativa) (FOLEY, 2005).

A polidez é um elemento imprescindível para que a interação se processe turno a turno adequadamente, sem conflitos, garantindo respeito às necessidades dos interlocutores, e para que transcorra de modo a alcançarem seus objetivos interacionais, conforme as normas de conduta vigentes na sociedade, em um continum que viabiliza o relacionamento cordial durante a interação, inclusive porque tanto o Presidente quanto os jornalistas se encontrarão em outros eventos comunicativos de entrevista e precisam estar guiados por relações anteriores de respeito e deferência, evidenciados em estratégias de polidez.

\section{Análise de dados}

Nos nossos dados, nos ocupamos da observação da negociação de atributos de identidades situadas do entrevistado para os entrevistadores jornalistas, isto é, as identidades formuladas a cada troca de turnos, conforme as tarefas interacionais de cada participante, realizadas a partir de suas identidades discursivas. Além da análise dos atos de ameaça à face dos jornalistas e as implicações interacionais, para as informações e para os telespectadores. 
A falta de deferência do Presidente da República com os jornalistas e os seguidos atos de ameaça à face positiva destes profissionais pode ser exemplificada por muitas das passagens em ambas as interações transcritas, mas principalmente nos segmentos selecionados, em que ridiculariza a pergunta do jornalista respondendo com conteúdo que permite a inferência de que as perguntas são impertinentes ou mesmo que não deveriam ter sido formuladas para ele.

Abaixo temos o primeiro segmento em análise, disponível no link https://youtu.be/aIpUbYjjdn0. Acesso em 20 jun. 2020, uma interação que, no total de 1 minuto e 32 segundos, foi transcrita em 39 linhas, mas para fins de análise, nos importa o segmento [JB01: 25-32]

Quadro 6 - Segmento [JB01: 25-32] - primeiro trecho da Análise de dados

\begin{tabular}{|l|l|l|}
\hline 25 & JOR 14: & é gradual $=$ \\
\hline 26 & JB: & \multicolumn{1}{c|}{$=$ é gradual e tem que voltar à normalidade $=$} \\
\hline 27 & JOR 1: & \multicolumn{1}{c|}{$=$} \\
\hline 28 & & tivemos mais de 300 mortes. quantas mortes o senhor acha \\
\hline 29 & & que- \\
\hline 30 & JB: & ah ô cara quem fala de- eu não sou coveiro tá certo \\
\hline 31 & JOR 1: & Presidente, mais uma coisa \\
\hline 32 & JB: & não sou coveiro \\
\hline
\end{tabular}

No primeiro segmento em análise, acima, o jornalista inicia o turno com uma afirmação sobre a quantidade de mortes em apenas um dia de pandemia no Brasil (linhas 27-29). Em seguida, inicia uma pergunta sobre a quantidade de mortes, mas seu turno sofre uma parada súbita e ele não consegue completar a pergunta. Podemos inferir que a continuação seria: quantas mortes o senhor acha que são suficientes para tomar uma atitude mais efetiva no controle de circulação das pessoas? Ou: Quantas mortes o senhor acha que ainda podem ocorrer diariamente durante a pandemia sem haver uma política pública de combate ao vírus? Vamos lembrar que esta interação ocorreu no dia 20/04/2020, ainda no início da pandemia por COVID-19 no mundo, em que a quantidade diária de mortes no Brasil ainda era "apenas" de 300 pessoas.

A resposta dada por Jair Bolsonaro (linha 30) indica falta de deferência com o profissional jornalista, de solidariedade com as pessoas mortas, que não são apenas números, e um alto nível de hostilidade. Impaciente, despreza o jornalista de forma desrespeitosa: "ah ô

\footnotetext{
${ }^{4}$ Destacamos que optamos por identificar os jornalistas entrevistadores por números porque, infelizmente, eles não apresentam seus nomes, a emissora de televisão para a qual trabalham nem seus rostos não são focalizados. A câmera foca o Presidente Jair Bolsonaro e alguns apoiadores, que se localizam à frente dos jornalistas no "cercado".
} 
cara”. Na sequência, afirma que quem fala de (parada súbita, em que o conteúdo é morte), é “coveiro”. E ele não é coveiro. No mínimo, desnecessária esta afirmação, porque o turno de pergunta do jornalista, que nem sequer pôde ser concluído (apenas chegou a um ponto relevante de transição sintática), claramente não foi projetado para um profissional coveiro, por não tratar especificamente do mandato institucional, isto é, do conjunto de deveres e direitos deste profissional que faz sepultamentos.

Ao contrário, a pergunta foi formulada para o Presidente da República, que toma o turno e se esquiva da resposta. Ao iniciar uma ação, um participante assume uma identidade situada particular e projeta uma identidade recíproca para o co-participante (ZIMMERMAN, 1998). Nesta atividade organizada sequencialmente, o jornalista projetou a identidade de Presidente para Bolsonaro e este não a admitiu, informando uma identidade que não é a sua, o que é reforçado ao jornalista tentar mudar de tópico discursivo (linha 31), já que Bolsonaro repete (linha 32): "não sou coveiro". A identidade de chefe de Estado foi reformulada e ocorreu o processo de elaboração de nova identidade por meio da negação, estratégia comum a Jair Bolsonaro, oposta à asserção, como se afastasse do comprometimento de quem ele é e do cargo que ocupa e como se reclamasse de o jornalista insistir em perguntar, desconsiderando que possivelmente mudaria o tópico discursivo.

O Presidente se sentiu desafiado pela pergunta do jornalista, como se este estivesse ameaçando sua face negativa, em tentativa de restringir sua liberdade de ação e domínio. Entretanto, é, sim, da competência de Presidente responder a um questionamento deste. Destaca-se que houve estratégia de polidez por parte do jornalista, solicitando e possibilitando que ele comentasse os números, reconhecendo sua face mais prestigiada como chefe de Estado, mas, infelizmente, em mais uma ocasião, como se viu ao longo de 2020, ele não tinha respostas para as questões concernentes à pandemia (e em 2021 ainda não as tem).

O segundo segmento em análise, abaixo, foi transcrito do link https://youtu.be/KGACSgIToUk. Acesso em 20 jun. 2020, no total de 44 segundos, em 20 linhas. Para fins de análise, vamos nos ater ao segmento [JB02: 01-09]

Quadro 7 - Segmento [JB02: 01-09] - segundo trecho da Análise de dados

\begin{tabular}{|l|l|l|}
\hline 01 & JOR 1: & a gente ultrapassou a china hoje no número de mortos. \\
\hline 02 & JB: & que que é? \\
\hline 03 & JOR 1: & a gente ultrapassou o número de mortos da china hoje. o Brasil \\
\hline 04 & JOR 2: & do coronavírus \\
\hline 05 & JB: & e daí? \\
\hline 06 & JOR 3: & o senhor não vai:: \\
\hline 07 & JB: & lamento. quer que eu faça o quê eu sou messias mas não faço \\
\hline 08 & & milagre \\
\hline 09 & APO: & $($ (risos) $)$ \\
\hline
\end{tabular}


No segundo segmento analisado, de 28/04/2021, disponibilizado acima, são 3 jornalistas, que se revezam para complementar o turno de pergunta ao Presidente Bolsonaro. O jornalista 1 inicia a interação com uma declaração de que naquela data ultrapassamos a China no número de mortos, o que por si só, já era uma situação a ser considerada com cautela pelas autoridades sanitárias brasileiras (linha 01). Bolsonaro parece não entender a informação ou não a ouvir e pergunta, com desdém, em mais uma ameaça à face positiva do jornalista, o que é que o jornalista estava dizendo ou do que ele queria implicar o Presidente na responsabilização (linha 2). O mesmo jornalista continua, faz autorreparo e repete a declaração, destacando que "a gente" quer dizer o Brasil (linha 3). O jornalista 2 complementa: "do coronavírus" (linha 4).

A resposta de Bolsonaro é ainda mais desrespeitosa (linha 5), não só com os jornalistas, mas principalmente, com o fato de termos, naquela ocasião, mais mortes de cidadãos brasileiros do que a China, país que naquele mês ainda era o epicentro da COVID-19 no mundo, que presenciou a morte de seus cidadãos antes mesmo de haver mais informações científicas sobre a origem e desenvolvimento da doença. Ele despreza: "E daí?", como se não fosse da sua competência tratar do tema de maneira responsável e interessada, deixando os jornalistas sem resposta e a população brasileira desassistida.

O jornalista 3 intervém (linha 6) e pergunta se "o senhor não vai”, com extensão da vogal final, como se deixasse que o Presidente complementasse com o comentário esperado desde o início da interação. Surpreendentemente, a omissão do Presidente se arrefece (linhas 7-8) e ele afirma que lamenta e, em seguida, faz uma pergunta retórica sobre o que querem que ele faça, como se não fosse de sua competência agir nem gerir esta crise no país. Ainda complementa abordando, de modo jocoso, que apesar de seu nome ser Messias (Jair Messias Bolsonaro), não faz milagres, como se esta capacidade fosse exigida de um chefe de Estado democrático. Prontamente, os apoiadores riem em coro (linha 9).

A resposta à pergunta, de fato, não houve e a interação pautou-se por ridicularização, em ato de ameaça à face positiva dos profissionais da imprensa, atacando-os na atividade profissional, que requer estima e apreciação. Além de mais um exemplo de descaso e irresponsabilidade com a população brasileira e espetáculo para a claque.

O terceiro segmento em análise, abaixo, é uma continuação do anterior, logo após os risos dos apoiadores, e segue até o fim da interação [JB02: 10- 20]. 
Quadro 8 - Segmento [JB02: 10-20] - terceiro trecho da Análise de dados

\begin{tabular}{|l|l|l|}
\hline 10 & JOR 3: & um plano pro ministro o ministro não vai apresentar um plano? \\
\hline 11 & JB: & o ministro que apresenta. \\
\hline 12 & JOR 3: & os números cita os números \\
\hline 13 & JB: & o ministro que apresenta, certo? \\
\hline 14 & JOR 3: & [cita os números] \\
\hline 15 & JB: & [ele pegou ] $\quad$ ministério andando né. as mortes de hoje a \\
\hline 16 & & princípio essas pessoas foram infectadas há duas semanas a \\
\hline 17 & & princípio. é o que eu digo pra vocês o vírus vai atingir setenta \\
\hline 18 & & por cento da população infelizmente é a realidade. é uma \\
\hline 19 & & realidade. mortes mortes ninguém nunca negou que haveriam \\
\hline 20 & & mortes. \\
\hline
\end{tabular}

Neste segmento interagem o Presidente Jair Bolsonaro e o jornalista 3, que questiona se "o ministro não vai apresentar um plano" (linha 10), em uma pergunta formulada com negação implícita indicando que a resposta esperada era que sim, vai apresentar. Bolsonaro responde: “o ministro que apresenta”, o que já havia sido pressuposto no turno de pergunta, que pela interação infere-se que a resposta esperada seria, por exemplo: O Ministro vai apresentar um plano no dia X. O jornalista pede que o colega jornalista 1 , que no segmento anterior informou que havíamos ultrapassado o número de mortes da China, cite os números (linhas 12 e 14). O presidente reforça que é o ministro que informa o plano (linha 13) e encerra seu turno com um marcador discursivo: "certo", o que é comum na fala de Bolsonaro, por vezes, ironizada pelo "está ok", grafado como "talkei”.

Bolsonaro toma o turno em sobreposição ao jornalista 3 (linhas 14-15) e passa a deter o piso conversacional ${ }^{5}$ até o fim da interação (linhas 15-20). Neste turno, o Presidente justifica que o plano do Ministro da Saúde para controle do vírus no Brasil ainda não foi apresentado porque "ele pegou o Ministério andando". Sabemos que o Ministro Luiz Henrique Mandetta foi demitido em 16/04/2020 e Nelson Teich assumiu em 17/04/2020, pedindo demissão em 15/05/2020. Como a interação ocorreu em 20/04/2020, o ministro Nelson Teich estava somente há 3 dias no cargo, entretanto, em função das tentativas frustradas de Mandetta ter apoio presidencial para implementar as medidas de distanciamento social para frear a propagação do vírus e externar o plano diariamente, às $17 \mathrm{~h}$, em entrevistas coletivas, era esperado que os jornalistas e a sociedade como um todo aguardassem ansiosamente o plano para combater o COVID-19 no nosso país. Se o tópico anterior da entrevista eram as mortes por COVID-19 no Brasil terem ultrapassado a China, a continuação da entrevista é sobre plano do Ministro da Saúde empossado.

\footnotetext{
${ }^{5}$ Piso conversacional caracteriza-se pela tomada de turno e sua manutenção.
} 
Destacamos a continuação do turno do Presidente que, sem citar o número de óbitos, justifica informando que as pessoas se infectaram há 2 semanas. E segue com um dado sem qualquer comprovação científica: $70 \%$ da população seria infectada pelo coronavírus - "uma realidade", segundo ele. Como prega negacionismo científico, carecer de dados e fontes em sua fala não são, em si, algo para nos surpreender. Em mais um exemplo de descaso, vocifera que "ninguém nunca negou de que haveriam (sic) mortes".

O ponto neste trecho é que o Presidente da República, ao ser entrevistado sobre a urgência de divulgação de um plano do Ministério da Saúde de combate à COVID-19, responde sem sustentar seus argumentos e ainda diz o óbvio: que sem qualquer plano ou política pública de saúde gerida pelo Governo Federal, haveria, sim, mortes. Mantém o turno para expressão um conteúdo absolutamente inútil, sabido de toda a população, e que não era esperado do Presidente da República.

\section{Considerações Finais}

Tendo em vista as análises dos dados transcritos de entrevista jornalística com o Presidente Jair Bolsonaro, apresentamos algumas considerações a respeito das identidades situadas do Presidente e dos atos de ameaça à face dos jornalistas, ocorridos no ano de 2020, quando, em 31 de março, foi declarada pela Organização Mundial da Saúde (OMS) que o mundo estava sofrendo uma pandemia (e ainda estamos, com mais mortes diariamente no Brasil e novas cepas do vírus).

As identidades discursivas de jornalista entrevistador e Presidente da República entrevistado são o padrão nas interações, entretanto nos turnos de resposta, Jair Bolsonaro ameaça a face dos jornalistas com marcas linguísticas e paralinguísticas que desprezam, ridicularizam e insultam jornalistas, o que revela hostilidade, como se nestas interações houvesse assimetria de poder imposta pelos profissionais da imprensa. Os jornalistas mantêm a deferência, fazem autorreparos e insistem nas perguntas, acreditando que, por força do mandato institucional, obterão respostas, mas não são bem-sucedidos porque o entrevistado não coopera para que a interação ocorra nem que continue.

Comporta-se de modo irritadiço frente as perguntas dos jornalistas, diferentemente do que se observa quando os militantes/apoiadores lhes fazem questionamentos ou solicitam que tome alguma atitude, pois nestes casos ele responde, dá atenção, aguarda que terminem seus turnos e fornece suas contribuições à medida do que é requerido. Além destas ações, critica a imprensa em coro com os apoiadores, que parecem ser incitados a desrespeitá-la. 
Turno a turno as identidades situadas foram negociadas pelo Presidente nas entrevistas, que optou por se eximir da responsabilidade com a sociedade brasileira na gestão de políticas públicas a cargo do Governo Federal de combate à COVID-19 ou à propagação do vírus em nosso território, diferentemente do que tem sido feito por outros governantes democraticamente eleitos pelo mundo. Ao invés dessas ações, advogou para si as identidades situadas de "não coveiro" e de quem "não faz milagre", evidenciando atitude pró-ativa de Presidente inapto por meio da negação.

Em seus turnos, ameaçou a face de jornalistas, ridicularizou a imprensa e não falou para todos os cidadãos brasileiros, restringindo-se aos apoiadores militantes que ficam a postos no "cercado" do Palácio do Alvorada para, sem máscaras, ouvir o Presidente vociferar contra a imprensa, a ciência, as instituições brasileiras em troca de risos e aplausos. É a necropolítica para a claque, que não atenta para o fato de ser também vítima.

\title{
INTERACTION REFUSAL AND FACE-THREATENING ACTS: PRESIDENT JAIR BOLSONARO VERSUS JOURNALISTS
}

\begin{abstract}
In this scientific article, we observe the discursive strategies in institutional speech turns in President Jair Bolsonaro's television interviews with journalists in two communicative situations, at the beginning of the COVID-19 pandemic in Brazil. We describe how journalists insist, on question turns, for effective answers from the President about control the pandemic in the country, but he, in answer turns, threatens the positive face of journalists and negotiates situated identities through denial, through what he is not, exempting himself from the responsibility of managing the health crisis. We use the theoretical and methodological assumptions of Conversation Analysis to transcribe the data and analyze the turn change and the Interactional Linguistics view to understand the interference of the institutional mandate and the setting in the identity negotiation actions, turn by turn.
\end{abstract}

KEYWORDS: COVID-19: Conversation analysis; COVID-19; journalistic interview; situated identities; Interactional linguistics.

\section{REFERÊNCIAS}

ALBERNAZ, Vinícius. Análise das Características do Discurso Populista de Jair Bolsonaro nas Eleições Brasileiras de 2018. In: Revista Portuguesa de Ciência Politica. 2019, n. 12, p. 131 146. DOI: $10.33167 / 2184-2078 . R P C P 2019.12 /$ pp.131-146

ALMEIDA, Ronaldo. Bolsonaro Presidente: Conservadorismo, evangelismo e a crise brasileira. In: Novos estudos CEBRAP. São Paulo. v. 38, n. 01, p.185-213. jan./ abr., 2019.

BROWN, P.; LEVINSON, S. Universals in Language Usage: Politeness Phenomena. In: GOODY, E.N. (ed.) Questions and Politeness - Strategies in social interaction. Cambridge: Cambridge University Pres, 1978.

AUTORA. Proję̧ão e Negociação de Identidades em Entrevistas com Candidatos à Presidência da República nas Eleições de 2002. 2004. 170 fl. Mimeo. Dissertação de Mestrado (Mestrado em Letras - Linguística) - Faculdade de Letras da Universidade Federal de Juiz de Fora, Juiz de Fora, 2004. 
CLARK, H. O uso da linguagem. In: Cadernos de Tradução. Instituto de Letras, UFRGS, n.9, jan.-mar, 2000.

DREW, P.; HERITAGE, J. Analysing talk at work: an introduction. In: Talk at work: Interaction in Institucional Settings. Cambridge: Cambridge University Press, 1992.

FOLEY, W. A. Anthropological Linguistics: An Introduction. Oxford: Blackwell Publishing, 2005.

FREITAG, Raquel Meister Ko.; CARDOSO, Paloma Batista; PINHEIRO, Bruno Felipe

Marques. Acho que é uma gripezinha: construções linguísticas como pistas de atitudes em tempos de pandemia. Revista Linguasagem, São Carlos, v. 35, Número temático COVID-19. Set./2020, p. 31-49.

GAGO, P. A relevância da convergência num contexto de Negociação: um estudo de caso de uma reunião empresarial na cultura portuguesa. 2002. 350 fl. Mimeo. Tese de Doutorado (Doutorado em Linguística e Língua Portuguesa) - Faculdade de Letras da Pontifícia Universidade Católica do Rio de Janeiro, Rio de Janeiro, 2002.

GARCEZ, P. Resenha de The discourse of Negotiation: Studies of language in the workplace. In: Language in Society, 25(3), p. 463-468, 1996.

GARCEZ, P. Formas institucionais de fala-em-interação e conversa cotidiana: elementos para a distinção a partir da atividade de argumentar. In: Palavra 8. Departamento de Letras da PUC-Rio. Rio de Janeiro: Editora Trarepa, 2002.

GOFFMAN, E. Interaction Ritual. New York: Pantheon, 1967.

GOFFMAN, E. Footing. In: GARCEZ, P.; RIBEIRO, B. Sociolinguística Interacional. Porto Alegre: Age, [1981] 1998.

MAYNARD, D. Inside Plea Bargaining: The Language of Communication. New York: Plenum Press, 1984.

MOITA LOPES, L. Práticas narrativas como espaço de construção das identidades sociais: uma abordagem socioconstrucionista. In: RIBEIRO, B.; LIMA, C.; DANTAS, M. Narrativa, Identidade e Clínica. Rio de Janeiro: Edições IPUB/CUCA, 2001.

MOITA LOPES, L. Identidades Fragmentadas: a construção discursiva de raça, gênero, e sexualidade em sala de aula. Campinas, SP: Mercado de Letras, 2002.

MORAIS, Argus Romero Abreu. O discurso político da extrema-direita brasileira na atualidade. Cadernos de Linguagem e Sociedade, 20(1), 2019.

SACKS, H. On the preferences for agreement and contiguity in sequences in conversation. In: BUTTON, G.; LEE, J. (eds.) Talk and Social Organization. Clevedon: Multilingual Matters, 1973.

SACKS, H.; SCHEGLOFF, E.; JEFFERSON, G. A Simplest Systematics for the Organization of Turn Taking for Conversation. In: Language, 50 (4), p. 696-735, 1974.

ZIMMERMAN, D. Identity, Context and Interaction. In: ANTAKI, C.; WIDDICOMBE, S. Identities in Talk. London: Sage, 1998.

Recebido em: 23/03/2021.

Aprovado em: 07/06/2021. 


\section{ANEXOS}

Transcrição completa dos dados analisados no artigo científico e reprodução da carta analisada

Dado 1: [JB01: 01-39], transcrito a partir de publicação no YouTube, disponível em: https://youtu.be/aIpUbYjjdn0. Acesso em 20 jun. 2020. A interação transcorreu em 1 minuto e 32 segundos, em 20/04/2020.

\begin{tabular}{|l|l|l|}
\hline 01 & JB: & uma boa notícia pra quem interessar, né. tive agora com o \\
\hline 02 & & governador Ibaneis eh conversamos da pos-si-bi-li-da-de de \\
\hline 03 & & abrirmos aqui da minha parte o colégio militar da parte dele os \\
\hline 04 & & colégios da pm, do bombeiro, bem como das escolas <cívico $>$ \\
\hline 05 & & militares a partir de segunda-feira= \\
\hline 06 & APO: & \\
\hline 07 & JB: & \\
\hline 08 & & talvez seja o primeiro gesto é:: pra nós aqui voltarmos a à \\
\hline 09 & & normalidade no tocante ao estudo aqui no Brasil= \\
\hline 10 & JOR 1: & \\
\hline 11 & & quando \\
\hline 12 & JB: & a partir de segunda-feira. não tá não tá batido o martelo ainda $=$ \\
\hline 13 & JOR 1: & \\
\hline 14 & & uma possibilida [de \\
\hline 15 & JB: & \\
\hline 16 & & ele: acha que a ideia é boa vai conversar com o chefe de gp \\
\hline 17 & & também entendeu? $<$ ministro da defesa $>$ márcio temos \\
\hline 18 & & conversado. vou conversar com moro também pra nós abrirmos \\
\hline 19 & & a academia da política federal a partir de segunda-feira também \\
\hline 20 & & existe essa POsibilidade, é que o moro tá viajando por isso não \\
\hline 21 & & consegui conversar com ele. \\
\hline 22 & JOR 1: & e os demais? \\
\hline 23 & JB: & va-vamos o primeiro passo é esse. porque os pais ainda tão \\
\hline 24 & & com medo ainda. os pais tão com medo então é natural \\
\hline 25 & JOR 1: & é gradual= \\
\hline 26 & JB: & \\
\hline 27 & JOR 1: & \\
\hline 28 & & tivemos mais de 300 mortes. quantas mortes o senhor acha \\
\hline 29 & & que- \\
\hline 30 & JB: & ah ô cara quem fala de- eu não sou coveiro tá certo \\
\hline 31 & JOR 1: & Presidente, mais uma coisa \\
\hline 32 & JB: & não sou coveiro \\
\hline 33 & JOR 2: & como foi a reunião com o ministro teich? \\
\hline 34 & JB: & ministro ministro? \\
\hline 35 & JOR 2: & da saúde, ministro da saúde. \\
\hline 36 & JB: & foi uma reunião rápida hoje ele tá arrumando nomes né pra \\
\hline 37 & & compor o ministério e é uma pessoa bastante equilibrada. ele \\
\hline
\end{tabular}




\begin{tabular}{|l|l|l|}
\hline 38 & quer se inteirar dos números pra poder realmente em cima de \\
\hline 39 & & números concretos traçar uma diretriz pra que lado ele vai. \\
\hline
\end{tabular}

Dado 2: [JB02: 01-20], transcrito a partir de publicação no YouTube, disponível em: https://youtu.be/KGACSgIToUk. Acesso em 20 jun. 2020. A interação transcorreu em 44 segundos, em 28/04/2020.

\begin{tabular}{|l|l|l|}
\hline 01 & JOR 1: & a gente ultrapassou a china hoje no número de mortos. \\
\hline 02 & JB: & que que é? \\
\hline 03 & JOR 1: & a gente ultrapassou o número de mortos da china hoje. o Brasil \\
\hline 04 & JOR 2: & do coronavírus \\
\hline 05 & JB: & e daí? \\
\hline 06 & JOR 3: & o senhor não vai:: \\
\hline 07 & JB: & lamento. quer que eu faça o quê eu sou messias mas não faço \\
\hline 08 & & milagre \\
\hline 09 & APO: & ((risos)) \\
\hline 10 & JOR 3: & um plano pro ministro o ministro não vai apresentar um plano? \\
\hline 11 & JB: & o ministro que apresenta. \\
\hline 12 & JOR 3: & os números cita os números \\
\hline 13 & JB: & o ministro que apresenta, certo? \\
\hline 14 & JOR 3: & [cita os números] \\
\hline 15 & JB: & [ele pegou \\
\hline 16 & & princípio essas pessoas foram infectadas há duas semanas a \\
\hline 17 & & princípio. é o que eu digo pra vocês o vírus vai atingir setenta \\
\hline 18 & & por cento da população infelizmente é a realidade. é uma \\
\hline 19 & & realidade. mortes mortes ninguém nunca negou que haveriam \\
\hline 20 & & mortes. \\
\hline
\end{tabular}

Dado 3 - Carta do Grupo Globo enviada ao GSI (Gabinete de Segurança Institucional) em: 25/05/2020. Disponível em: https://oglobo.globo.com/brasil/falta-de-segurancafaz-jornalistas-do-grupo-globo-deixar-plantao-no-alvorada-1-24445585 Acesso em 20 jun. 2020

"Ao cumprimentar V.Exa., trazemos ao conbecimento desse Gabinete uma questão que envolve a segurança da cobertura jornalística no Palácio da Alvorada. É público que o Senhor Presidente da República na saída, e muitas vezes no retorno ao Palácio, desce do carro e dá entrevistas, bem como cumprimenta simpatizantes. Este fato fez vários meios de comunicaşão deslocarem para lá equipes de reportagem no intuito de fazer a cobertura.

Entretanto são muitos os insultos e os apupos que os nossos profissionais vêm sofrendo dia a dia por parte dos militantes que ali se encontram, sem qualquer segurança para o trabalho jornalístico.

Estas agressões vêm crescendo. 
Assim informamos por meio desta que a partir de hoje nossos repórteres, que têm como incumbência cobrir o Palácio da Alvorada, não mais comparecerão àquele local na parte externa destinada à imprensa.

Com a responsabilidade que temos com nossos colaboradores, e não havendo segurança para o trabalho, tivemos que tomar essa decisão

Respeitosamente,

Paulo Tonet Camargo

Vice-Presidente de Relações Institucionais

Grupo Globo" 